\title{
Layout of the First-Mining Working Face in the Protected Seam for Pressure Relief by Peak Stress Shift
}

\author{
Xiao-Xu Gao, Guo-Jin Chai, and Guang-An Zhu \\ School of Energy Engineering, Xi'an University of Science and Technology, Xi'an, Shaanxi 710054, China \\ Correspondence should be addressed to Guang-An Zhu; zhuguangan@163.com
}

Received 30 January 2021; Revised 23 February 2021; Accepted 5 March 2021; Published 15 March 2021

Academic Editor: Xiaowei Feng

Copyright (C) 2021 Xiao-Xu Gao et al. This is an open access article distributed under the Creative Commons Attribution License, which permits unrestricted use, distribution, and reproduction in any medium, provided the original work is properly cited.

\begin{abstract}
An appropriate layout of the first-mining working face of protected seams is key to rockburst prevention in coal seams. By taking the first-mining working face in the 2-2\# middle coal seam in Hulusu Coal Mine as the background, a mechanical model for the stress distribution after mining the upper protective seams was established through theoretical analysis and in situ measurement. The problem concerning the layout of the first-mining working face in the protected seam was transformed into one concerning the optimal horizontal distance $L$. Furthermore, based on the theory of stress transfer within a semi-infinite plane, the distribution of the vertical stress in the protected seam was deduced, for which numerical simulation was performed. Through calculation, it is best (in terms of roadway excavation) to set $L$ to between 50 and $75 \mathrm{~m}$; the mining-induced disturbance shows the least influence on the two roadways at $L=80$ to $140 \mathrm{~m}$ and at $L=40$ to $100 \mathrm{~m}$, and the influence of the remaining coal pillar on mining of the working face is the least significant. Based on the analytic hierarchy process (AHP) evaluation method, the weights of three groups of contradictory criteria and the weighted values of the peak stress under different values of $L$ were calculated. The results show that the global stress on the first-mining working face in the protected seams is lowest at $L=60 \mathrm{~m}$. The results can provide a reference for the layout of the working faces in protected seams in adjacent coal mines.
\end{abstract}

\section{Introduction}

Rock burst is a typical dynamic disaster in deep coal mining through the world and usually induces momentary gateway deformation and failure, casualties, and, more seriously, a series of secondary disasters, such as coal and gas outburst, gas explosion [1-6]. In recent years, the number of the coal mines subjected to rockburst accidents in the Inner Mongolia Autonomous Region and Shaanxi Province, China, has increased year-over-year; however, restricted by the prevailing geological conditions in these areas and the as-formed mining layout, only local measures can be taken; consuming much resource often has little effect. Advancement in some areas is considered as the principle of preventing and controlling the risk of a rockburst in coal mines while techniques involving protective seams are effective as a means of prevention. The measure is particularly applicable to prevention and control of the closely spaced rockburst-prone coal seams in the Inner Mongolia Autonomous Region and Shaanxi Province.
At present, research on the effect of the rockburst prevention in protective seams mainly concentrates on the protective distance, the pressure-relief range, stress-recovery level, vibration-suppression, and the influence of the remaining coal pillars [7-12]. How to distribute working faces in protected seams for pressure relief by peak shift has become the focus of research into this matter. Xie et al. [13] investigated the distribution of abutment pressures in Liangbei Coal Mine in Xinfeng, No. 10 mine (Pingdingshan Tianan Coal Mining Group), and Huafeng Mine (Shandong Energy Xinwen Mining Group Co., Ltd.) after the mining of their upper protective seams. Furthermore, they modelled the pressure-relief (and its extent) arising on the upper pressure-relief seams. By taking Jisan Coal Mine (Shandong Province, China) as the background, Wu et al. [14] and Lv et al. [15] suggested that the maximum rate of stress release from coal in such protected seams can reach $19.2 \%$ after mining protective seams. By performing simulation tests with similar materials, Wang et al. [16] and Tang et al. [17] 
calculated a reasonable pressure-relief angle for the protective seams and determined the best position of the lower gangway in the nearby protected seams. By combining numerical simulation with tests using similar materials, Pang et al. [18] explored the rockburst-weakening mechanism of protective seams below superthick conglomerate layers, allowing better disposition of the working faces.

The aforementioned studies are based on old mining areas (in Shandong Province, Henan Province, and Northeast China) where the mining layout has already been implemented. Due to disparities in various conditions such as the mining depth, lithology of roofs and floors, and geological structure, these studies offer less guidance to those working in new mining areas, where the first-mining working face in lower coal seams has not yet been accessed such as in the Inner Mongolia Autonomous Region and Shaanxi Province, China. Moreover, scholars have explored several key problems (such as stress distribution, pressurerelief range, the effects of remaining coal pillars, layer spacing, and their influences on mining) pertaining to the mining of protective seams, without comprehensive consideration having been given to the holistic nature of the problem. No specific solution is proposed when multiple factors concur and are interactively restricted; investigation on the layout of working faces for pressure relief by peak shift considering multiple influencing factors by taking the first-mining working face as the background is thus deemed important.

The layout of the first-mining working face in the 2-2\# middle coal seam of Hulusu Coal Mine in the Inner Mongolia Autonomous Region was explored. A mechanical model for stress distribution in coal after mining protective seams was established based on limit equilibrium theory and in situ measurements; thereafter, the formula for the vertical stress distribution in protected seams was deduced based on the theory of stress transfer in a semi-infinite plane as revealed through numerical simulation. The stress distributions on the working faces in protected seams at different mining stages and the influence of the remaining coal pillar in the middle part were comprehensively considered. On this basis, an analytic hierarchy process (AHP) method for determining the optimal horizontal distance $L$ was proposed: this can provide information about the best layout of the first-mining working face in mines whose second coal seam is about to be mined in the Inner Mongolia Autonomous Region and Shaanxi Province.

\section{Engineering Profile}

The 2-1\# coal seam and 2-2\# middle coal seam of Hulusu Coal Mine were mined from top to bottom. Within the panel, the 2-1\# coal seam had an average burial depth of $646.4 \mathrm{~m}$, and the spacing between the 2-2\# middle coal seam and the overlying coal seam was 13.35 to $30.57 \mathrm{~m}$, with a mean spacing of $26 \mathrm{~m}$. At present, the 21102 and 21103 working faces in the $2-1 \#$ coal seam had been mined. The width of both goafs was $320 \mathrm{~m}$, and the width of the remaining coal pillar between goafs was $30 \mathrm{~m}$. The coal seam thickness varies from 1.7 to $3.0 \mathrm{~m}$ with an average angle of $2^{\circ}$.
The roof strata are mainly composed of fine/medium sandstone with a thickness of 13-23m. Excavation of three roadways to the east of the 2-2\# middle coal seam had been finished and the 22103 working face would be laid out. It was planned to distribute three roadways (a ventilation roadway, a main haulage roadway, and an auxiliary haulage roadway from west to east) in the 22103 working face with a width of $320 \mathrm{~m}$ and a sectional coal pillar some 20 to $30 \mathrm{~m}$ wide. The position of the 22103 working face is shown in Figure 1.

The $2-1 \#$ coal seam was close to the $2-2 \#$ middle coal seam, and two goafs in the former were formed within a short time; moreover, the 2 -1\# coal seam served as a protective seam for the mining of the 2-2\# middle coal seam. Therefore, during the layout of the 22103 working face, it was essential to distribute the three main roadways therein in the low-stress zone formed during the mining of the 2-1\# coal seam while avoiding zones of stress concentration formed around the sectional coal pillar. By doing so, the layout of the working face for pressure relief by peak shift could be realised.

\section{The Mechanical Model for Layout of the Working Face in the Protected Seam for Pressure Relief by Peak Shift}

3.1. Stress Distribution of Coal after Mining the Upper Protective Seam. To solve the above problem, the geological and mining technical conditions of Hulusu Coal Mine are simplified. On the dip section, a coordination system is established by taking the bottom at the margin of the 21102 goaf as the origin. In this way, the mechanical model for the overburden structure and stress distribution after mining the 2-1\# coal seam is attained (Figure 2). In the model, the widths of the 21102 goaf, 21103 goaf, and 22103 working face are all $320 \mathrm{~m}$; the remaining coal pillar in the $2-1$ \# coal seam has a width of $30 \mathrm{~m}$ and the sectional coal pillar in the 21101 ventilation roadway also has a width of $30 \mathrm{~m}$. The spacing between the two coal seams is $26 \mathrm{~m}$. The horizontal distance between the 22103 working face and the upper slice in the 21102 working face is set to $L$. Therefore, the problem of optimising the layout of the first-mining working face in the 22103 coal seam corresponds to that requiring the best value of $L$ on the dip section.

As shown in Figure 1, $L$ is mainly influenced by two factors, including (1) the effective pressure-relief range of the goaf in the 2-1\# coal seam: it is necessary to avoid distributing the three main roadways in the influence areas of the advanced abutment pressure and in the stress-recovery zone in the middle of the goaf in the $2-1 \#$ coal seam; (2) the range of influence of the remaining coal pillar in the middle part of the goaf in the 2-1\# coal seam: it is necessary to avoid distributing the three main roadways in the area of influence of the remaining coal pillar and minimise the stress thereon (as it lies in the critical middle part of the working face) during mining.

It can be seen from Figure 2 that, after mining the 2-1\# coal seam, three areas apply load to the 2-2\# coal seam: the zone of influence of the advanced abutment pressure in the 


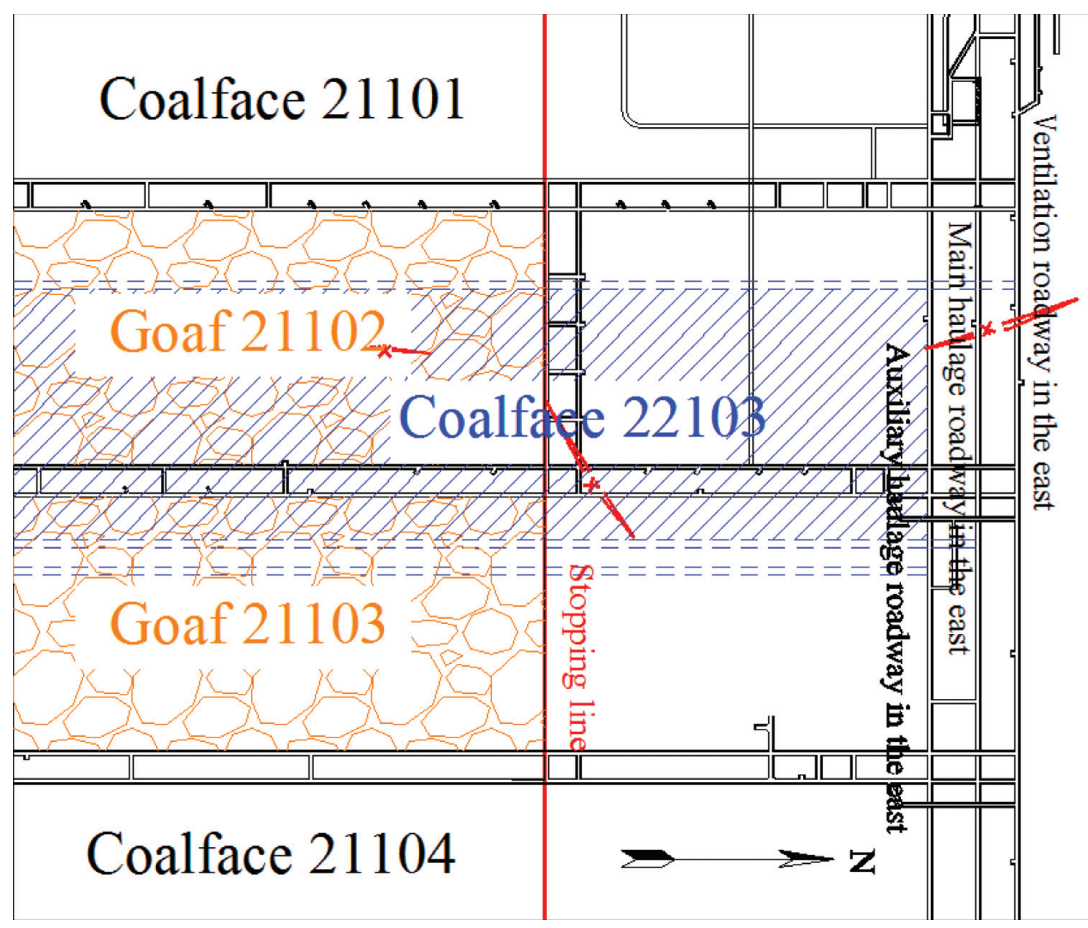

FIGURE 1: Overview of the 22103 working face.

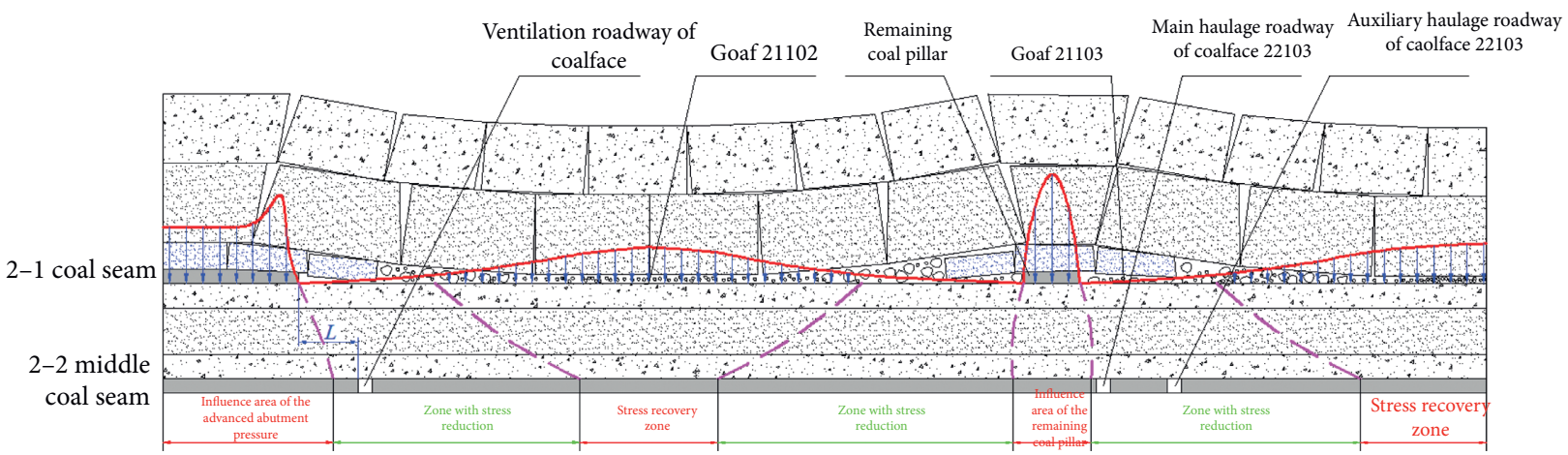

Figure 2: The model for the overburden strata and the stress distribution of coal after mining the upper protective seam.

21101 ventilation roadway, the stress-recovery zone in the goaf, and the zone of influence of the remaining coal pillar. Scholars have investigated the distribution of the zones of influence of the advanced abutment pressure in the working face. The coal pillar is divided into elastic and plastic zones by mainly employing the theory of elastic-plastic limit equilibria $[19,20]$. The vertical stress $\sigma_{y}$ within the plastic zone is given by

$$
\sigma_{y}=N_{0} \frac{1+\sin \varphi}{1-\sin \varphi} e^{-2 f x / M(1-\sin \varphi / 1+\sin \varphi)} \quad\left(-x_{0} \leq x<0\right) .
$$

It is supposed that the range of the plastic zone in the coal seam corresponds to $x_{0}$; then, the abutment pressure reaches its peak at $x_{0}$. Assuming the peak of the abutment pressure satisfies $\sigma_{y \max }=K \gamma h, x_{0}$ can be calculated by using the following formula:

$$
x_{0}=\frac{M}{2 f} \frac{1+\sin \varphi}{1-\sin \varphi} \ln \left(\frac{K \gamma h}{N_{0}} \frac{1-\sin \varphi}{1+\sin \varphi}\right) .
$$

The abutment pressure distribution in the elastic zone can be calculated according to the following formula:

$$
\sigma_{y}=K \gamma h e^{2 f / \lambda M\left(x_{0}+x\right)} \quad\left(x<-x_{0}\right) .
$$

The stress distribution in the remaining coal pillar between goafs in the two sides can be also calculated based on the theory of limit equilibria. The range of the plastic zone and the width of the coal pillars are separately set to $x_{1}$ and $B$. When $B>2 x_{1}$, the part subject to increasing stress within the elastic zone on the two sides of the coal pillar is not superimposed upon the middle part of the coal pillar, and the in situ stress distribution zone is present in the centre of the coal pillar. In this case, the remaining coal pillar can still be divided into a plastic zone, an elastic zone, and a plastic 
zone (from the edge to the middle), and the stress distributions therein are symmetrical.

According to the measured stresses on the working face, the peak stress in the 21103 working face is found acting within a range of about $8 \mathrm{~m}$ in front of the coal wall, so $x_{1}=8 \mathrm{~m}$ and $B=30 \mathrm{~m}$, satisfying $B>2 x_{1}$. Therefore, a certain in situ stress distribution zone still appears in the remaining coal pillar, the vertical stress on which can be calculated using formulae (1) to (3). Exploiting symmetry, the distribution of the vertical stress within the remaining coal pillar is expressed as follows:

$$
\left\{\begin{array}{l}
\sigma_{y}=\tau_{0} \cot \varphi \frac{1+\sin \varphi}{1-\sin \varphi} e^{2 f(x-320) / M(1-\sin \varphi / 1+\sin \varphi)} \quad\left(320 \leq x \leq 320+x_{1}\right), \\
\sigma_{y}=K \gamma h e^{2 f / \lambda M\left(x_{0}-x+320\right)} \quad\left(320+x_{1}<x \leq 335\right), \\
\sigma_{y}=K \gamma h e^{2 f / \lambda M\left(x_{0}+x-350\right)} \quad\left(335<x \leq 350-x_{1}\right), \\
\sigma_{y}=\tau_{0} \cot \varphi \frac{1+\sin \varphi}{1-\sin \varphi} e^{(2 f(350-x)) / M(1-\sin \varphi / 1+\sin \varphi)} \quad\left(350-x_{1} \leq x \leq 350\right),
\end{array}\right.
$$

where $N_{0}, \varphi, f, M, K$, and $\gamma$ refer to the support force of the coal walls, the internal friction angle of coal, friction coefficient between layers, thickness ( $\mathrm{m}$ ) of coal seams, stressconcentration factor, and bulk density $\left(\mathrm{kN} / \mathrm{m}^{3}\right)$ of the overlying strata, respectively; $h, x$, and $\lambda$ represent the burial depth $(\mathrm{m})$ of the coal seam, the distance $(\mathrm{m})$ of any point to the coal wall (s), and the lateral pressure coefficient on the plane of maximum ultimate strength, respectively.

As for the goafs, King and Whittaker [21] showed that the stresses therein can recover to a level approximate to the in situ stress with the increase in the area of the goafs, thus forming stress-recovery zones, which are symmetrically distributed along the centre of the goafs. Mark [22] and Choi and McCain [23] all derived empirical formulae for the distance required for stress recovery in goafs. They suggested that the distance required for stress recovery is linearly correlated with the burial depth $h$ of coal seams and the tangent value of the expansion angle $\beta$ of the lateral abutment pressure (the diffusion angle of surface subsidence); that is,

$$
x_{a}=h \tan \beta,
$$

where $x_{a}$ refers to the distance required for stress recovery in goafs to a level approximate to the in situ stress and $\tan \beta$ takes different values under different geological conditions; however, research results indicate that $\tan \beta$ is generally between 0.3 and 0.4 (a value of 0.3 was adopted here).

The burial depth of the 2-1\# coal seam in Hulusu Coal Mine is estimated to be $650 \mathrm{~m}$. On this basis, it is estimated that the stress in the middle part of the 21102 goaf recovers to about 0.82 times the in situ stress. Accordingly, $\sigma_{y}$ in the goaf is expressed as follows:

$$
\left\{\begin{array}{l}
\sigma_{y}=0.82 \gamma H x \quad(0 \leq x \leq 160) \\
\sigma_{y}=-0.82 \gamma H(x-320) \quad(160 \leq x \leq 320) \\
\sigma_{y}=0.82 \gamma H(x-350) \quad(350 \leq x \leq 510) \\
\sigma_{y}=-0.82 \gamma H(x-670) \quad(350 \leq x \leq 670) .
\end{array}\right.
$$

3.2. Stress Distribution on the Coal in the Protected Seam. According to the theory of elastic mechanics as applied to a semi-infinite plane, the stress $\sigma_{y}$ applied to the floor of a coal seam can be simplified as the integral of the load across an infinite number of microunits. As shown in Figure 3, the stress $\sigma_{y}^{\prime}$ induced at any point $M(x, y)$ in the floor strata can be expressed as follows:

$$
\sigma_{y}^{\prime}=\frac{2}{\pi} \int_{-b}^{a} \frac{\sigma_{y} y^{3}}{\left[(x-\xi)^{2}+y^{2}\right]^{2}} d \xi,
$$

where $-b$ and $a$ are constants, which separately represent the upper and lower limits of $\sigma_{y}$ applied along the direction of the $x$-axis; $\varphi$ and $\xi$ refer to the internal friction angle of coal and the horizontal coordinate of each microunit, respectively; and $x$ and $y$ separately denote the horizontal and vertical coordinates of any point in the floor strata.

Therefore, the distribution of vertical stress within the protected seam (the 2-2\# middle coal seam) can be calculated by simply substituting the piecewise function $\sigma_{y}$, formed by simultaneously calculating formulae (1), (3), (4), and (6), into formula (7) and setting $y=24 \mathrm{~m}$; however, the estimated function $\sigma_{y}$ for the stress distribution in the protected seam is complicated and some parameters therein are difficult to determine accurately, making analysis of the optimal layout of the working face for pressure relief by peak-shift complicated. Further investigation is thus required and numerical simulation was used.

\section{Quantitative Analysis of the Horizontal Distance $L$}

According to Figure 2 and the borehole histogram of the working face, a FLAC numerical model for the distribution of stress on the 22103 working face is established: the model simulated a region measuring $1000 \mathrm{~m} \times 280 \mathrm{~m}$ (Figure 4). In the model, the thicknesses of both the 2-1\# coal seam and 2- 


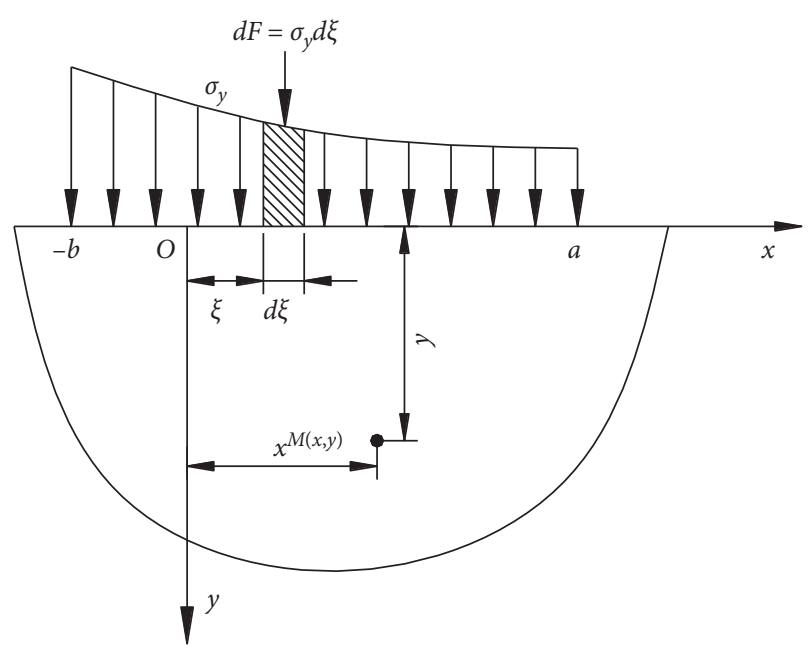

Figure 3: The model of load on the floor after mining the protective seam.

2\# middle coal seam are $3 \mathrm{~m}$ and the spacing between them is $26 \mathrm{~m}$; moreover, the 2-2\# middle coal seam is buried at a depth of $660 \mathrm{~m}$, with a dip angle of $0^{\circ}$. The Mohr-Coulomb constitutive model is applied to model the coal and rock mass, whose physicomechanical parameters are determined according to laboratory test results. Fixed conditions are applied to the bottom, left, and right-hand boundaries of the model, that is, both the horizontal and vertical displacements of the boundaries are zero; the displacement of the top boundary of the model is calculated according to the burial depth of the coal seam and a uniformly distributed load is applied. Table 1 lists the mechanical properties of the materials used in the model.

The numerical simulation was conducted according to the following scheme: (1) the 2-1\# coal seam was excavated, in which the 21101 ventilation roadway; then the 21102 and 21103 working faces were successively excavated. The monitoring lines for stress are distributed along the floor of the 2-2\# middle coal seam, and then the distribution of vertical stress in the 2-2\# middle coal seam at different stages in the mining of the 2-1\# coal seam is calculated. Furthermore, the horizontal distance $L$, which is most beneficial to the excavation of the 22103 working face, is determined; (2) the 22103 working face is excavated. The horizontal distance $L$ between the 22103 working face and the upper slice $(21102$ working face) is separately set to $0,20,40,60,80,100,130$, and $160 \mathrm{~m}$. The monitoring lines for stress are distributed along the roof of the 2-2\# middle coal seam. On this basis, the distribution of the vertical stress on the 22103 working face is calculated and the horizontal distance $L$, which is most beneficial to the mining of the 22103 working face, is determined.

4.1. Optimising the Horizontal Distance L for Roadway Excavation in the 22103 Working Face. After completely mining the 2-1\# coal seam as the upper protective seam, the nephogram of the distribution of vertical stress in the stope after mining the coal seam is as shown in Figure 5: two zones subjected to a reduction in stress (i.e., the 21102 and 21103 pressure-relief zones), the zone of influence of the remaining coal pillar and the two zones subjected to stress growth (stress-recovery zones) are formed after the mining of the 21\# coal seam. To realise quantitative analysis thereof, the distribution of the vertical stress on the 2-2\# middle coal seam is plotted (Figure 6(a)). The points of the lowest vertical stress on the 2-2\# middle coal seam separately have horizontal coordinates of $x=215 \mathrm{~m}$ and $x=565 \mathrm{~m}$. On this condition, the vertical stresses on the 2-2\# middle coal seam are separately equivalent to 2.648 and $3.682 \mathrm{MPa}$. The horizontal coordinate of the coal area in the 2-1\# coal seam is determined as $x=165 \mathrm{~m}$; therefore, in the ideal case, the 22103 ventilation roadway and main haulage roadway should be synchronously distributed at the two points of lowest stress. However, the coal mine operators have set the length of the working face to $320 \mathrm{~m}$, so from the production perspective, it is necessary to expand the low-stress zone to distribute the three roadways in a coordinated fashion. On this basis, the relationship between the horizontal distance $L$ and the vertical stress in the three roadways is plotted (Figure 6(b)). Through analysis, it can be found that with increase in $L$, the stress on the ventilation roadway first increases, then decreases, then increases again, before finally decreasing, while the stresses on both the main and auxiliary haulage roadways first decrease and then increase. Thus, the three roadways fail to be synchronously distributed in areas subject to the lowest vertical stress under current conditions. By fitting the data, the range around the intersection of the three stress curves, that is, $L \approx 50$ to $75 \mathrm{~m}$, is taken as the horizontal distance most conducive to roadway excavation of the 22103 working face.

4.2. Optimising L for the Mining of the 22103 Working Face. After excavating the 2-1\# coal seam, the 22103 working face is excavated according to the horizontal distances $L$ of 0,20 , $40,60,80,100,130$, and $160 \mathrm{~m}$. After the model reaches equilibrium, the nephogram of the distribution of vertical stress in the stope is drawn (Figure 7): three zones of stress concentration (i.e., the zones of influence of the advanced abutment pressure on two sides of the working face and that of the remaining coal pillar) are mainly formed after mining the 22103 working face on condition of having a reasonable value of $L$. Given an unreasonable value of $L$, the two zones subject to increasing stress are in close proximity and they may overlap, increasing the risk of strata deformation during the mining of the working face. The distribution of the vertical stresses on the three stress-concentration zones under different horizontal distances $L$ is shown below.

4.2.1. The Zones of the Advanced Abutment Pressure in Two Roadways of the 22103 Working Face. The distributions of vertical stress in the zone of influence of the advanced abutment pressure of the ventilation roadway in the 22103 working face under different horizontal distances $L$ are displayed in Figure 8(a). It can be found that the vertical stress distributions are similar; however, the peak stress first decreases and then increases with increasing $L$. By using the 


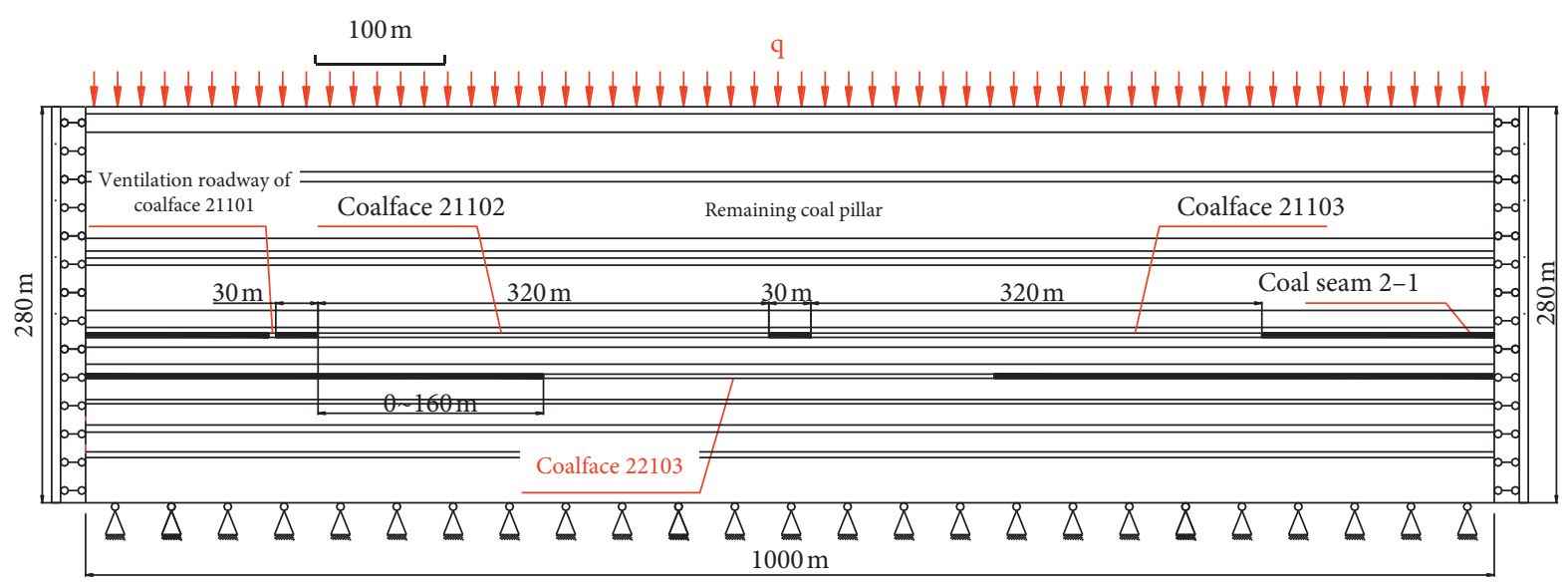

FIGURE 4: FLAC numerical model after mining the protective seam.

TABle 1: Properties of coal and rock mass used in the numerical model.

\begin{tabular}{|c|c|c|c|c|c|c|}
\hline & Density $\left(\mathrm{Kg} / \mathrm{m}^{3}\right)$ & Bulk (GPa) & Shear $(\mathrm{GPa})$ & Cohesion $(\mathrm{MPa})$ & Friction angle $\left({ }^{\circ}\right)$ & Tension $(\mathrm{MPa})$ \\
\hline Fine sandstone & 2600 & 5.56 & 4.17 & 2.0 & 35 & 2.5 \\
\hline Siltstone & 2700 & 2.68 & 1.84 & 2.0 & 32 & 2.0 \\
\hline Coarse sandstone & 2760 & 2.80 & 2.00 & 2.3 & 34 & 2.3 \\
\hline Medium sandstone & 2800 & 6.00 & 5.00 & 3.0 & 38 & 3.0 \\
\hline Conglomerate & 2660 & 4.65 & 2.78 & 2.0 & 34 & 2.4 \\
\hline Coal seam $2-1$ & 1400 & 1.19 & 0.37 & 0.8 & 23 & 0.5 \\
\hline Coal seam 2-2 middle & 1450 & 1.25 & 0.43 & 1.0 & 25 & 0.8 \\
\hline Mudstone & 2200 & 3.03 & 1.56 & 1.2 & 27 & 1.0 \\
\hline
\end{tabular}

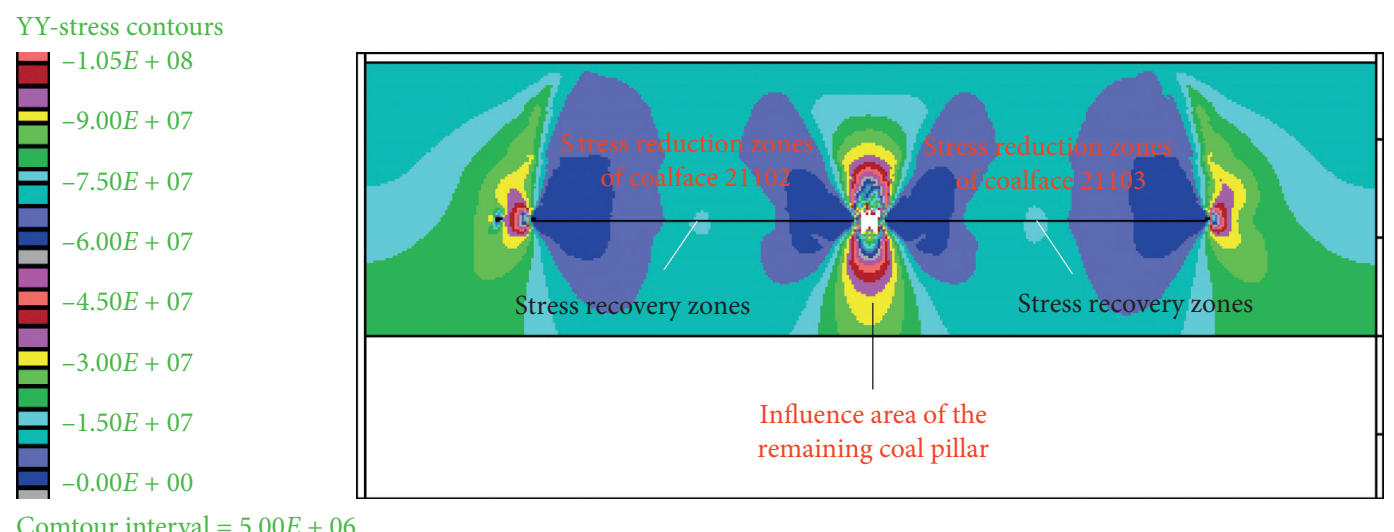

FIgURE 5: Nephogram of the distribution of vertical stress after mining the 2-1\# coal seam.

same data processing method, the stress distributions in the zone of influence of the advanced abutment pressure in the haulage roadway were analysed, and a comparison was made between the peak stresses occurring in the two roadways (Figure $8(\mathrm{~b})$ ). At $L=20 \mathrm{~m}$, the vertical stress on the side of the 22103 ventilation roadway is the lowest while that on the side of the haulage roadway is the largest. For $L>20 \mathrm{~m}$, the vertical stress on the side of the ventilation roadway gradually increases while that on the side of the haulage roadway decreases. For $L>130 \mathrm{~m}$, the vertical stress on the side of the haulage roadway exceeds that on the side of the ventilation roadway, so the stresses on the two roadways under the horizontal distance $L$ at the intersection of the two curves are in the most stable equilibrium (i.e., optimally conducive to mining of the working face). By fitting the data, it can be found that $L \approx 110 \mathrm{~m}$ at the intersection. Considering likely errors, a range of $30 \mathrm{~m}$ before and beyond the intersection (that is, $L=80$ to $140 \mathrm{~m}$ ) is taken as the horizontal distance showing the weakest influence on the zones of influence of the advanced abutment pressure in the two roadways.

4.2.2. Stress Distribution in the Zone of the Remaining Coal Pillar. Under different horizontal distances $L$, the distributions of vertical stress in the zone of influence of the remaining coal pillar above the roof of the 22103 working 


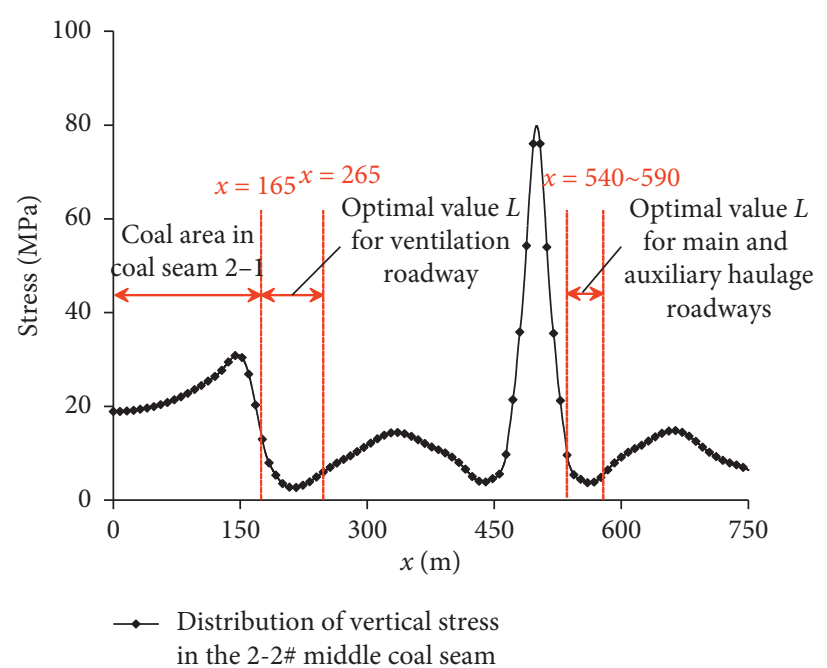

(a)

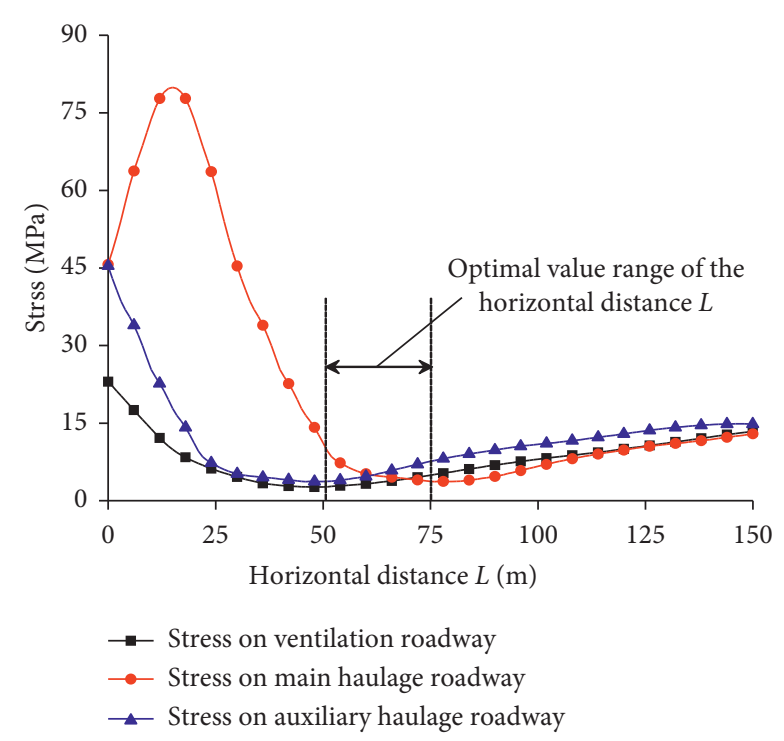

(b)

FIgURE 6: Quantitative analysis of the horizontal distance $L$ most conducive to roadway excavation. (a) The distribution of vertical stress on the 2-2\# middle coal seam. (b) The optimal values of $L$.

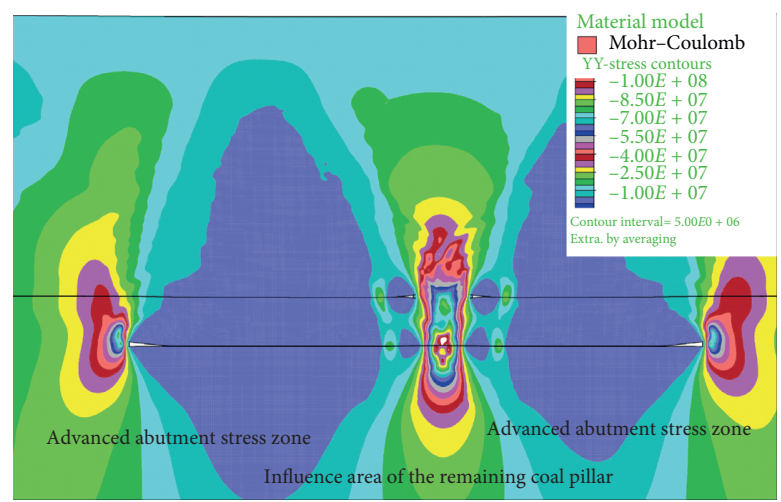

(a)

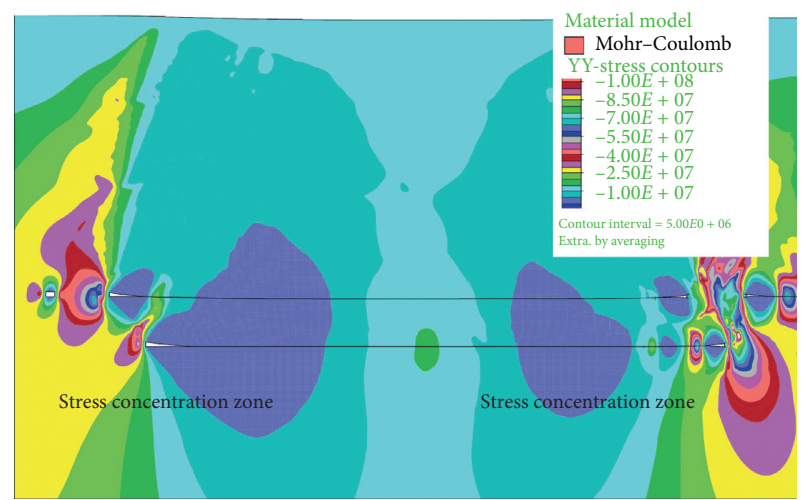

(b)

FiguRE 7: Distribution of the stress-concentration zones in the working face during mining under different horizontal distances $L$. (a) $L=160 \mathrm{~m}$ (three stress-concentration zones). (b) $L=20 \mathrm{~m}$ (two stress-concentration zones).

face are shown in Figure 9(a). It can be seen that, due to the superposition of peak stresses, the peak stress deviates from a position just below the coal pillar owing to the 21103 haulage roadway being close to that area influenced by the remaining coal pillar when $L<20 \mathrm{~m}$; however, a high level of stress concentration is still formed, which is unfavourable to the mining of the working face. By analysing the peak stresses, the stress distribution is plotted in Figure 8(b) wherein the peak stress first increases, decreases, then increases, and finally decreases again with increasing $L$. At $L=40 \mathrm{~m}$, the vertical stress in the zone of influence of the remaining coal pillar is the lowest. Considering the likely error, the range from the inflection point to the next inflection point (that is, $L=40$ to $100 \mathrm{~m}$ ) is considered as the horizontal distance, under which the remaining coal pillar exerts the weakest influence on the mining of the working face.
4.3. AHP Method for Determining the Optimal Horizontal Distance L. According to the analysis above, it can be seen that it is necessary to consider the influences of the roadway excavation, abutment pressure in the two roadways, and remaining coal pillar when determining the horizontal length $L$ of the working face in the protected seam. Moreover, the optimal values of $L$ determined according to the three factors are 50 to 75,80 to 140 , and 40 to $100 \mathrm{~m}$, respectively. It is impossible to have a value of $L$ which synchronously satisfies three criteria, and only those ranges from 50 to 75 and 80 to $100 \mathrm{~m}$ satisfy two criteria. Therefore, the AHP method is used to perform analysis to compare the optimal values of $L$. The comprehensive weight of $L$ is determined by considering the relative importance of the three factors.

According to the concept of AHP, a target layer A, conditional layers $\mathrm{B}$, and factor layers $\mathrm{C}$ for the layout of the working face in the protected seam for pressure relief by 


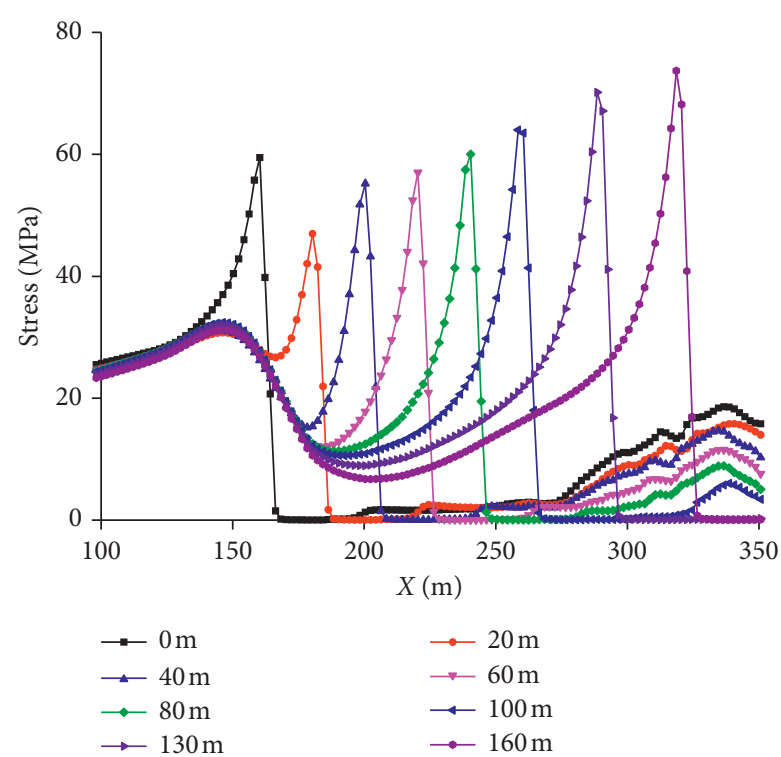

(a)

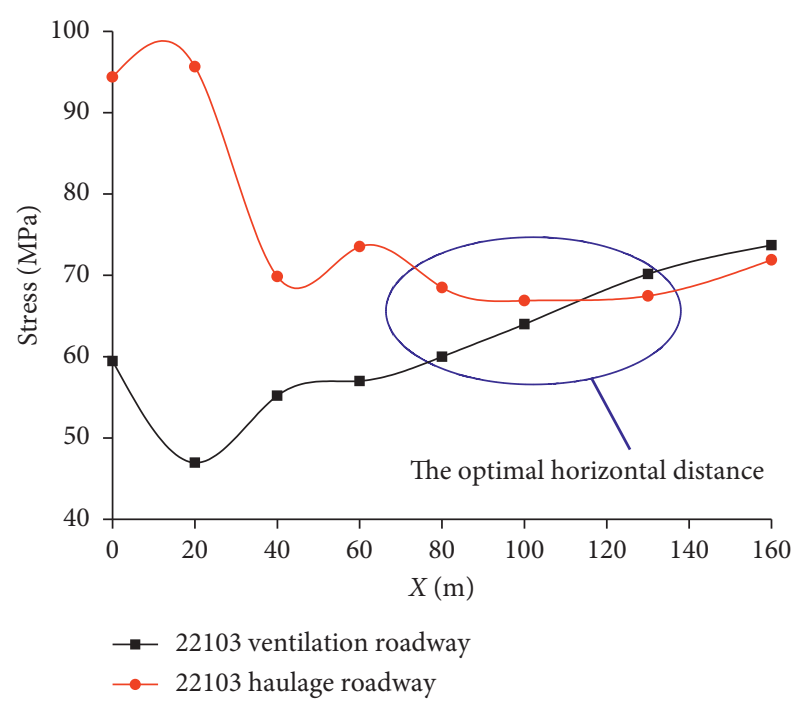

(b)

FIGURE 8: Distribution of the vertical stress in the influence areas of the advanced abutment pressure in the two roadways during the mining under different horizontal distances $L$. (a) Curves of the vertical stress in the ventilation roadway for different values of $L$. (b) Comparison of the vertical peak stresses in the two roadways.

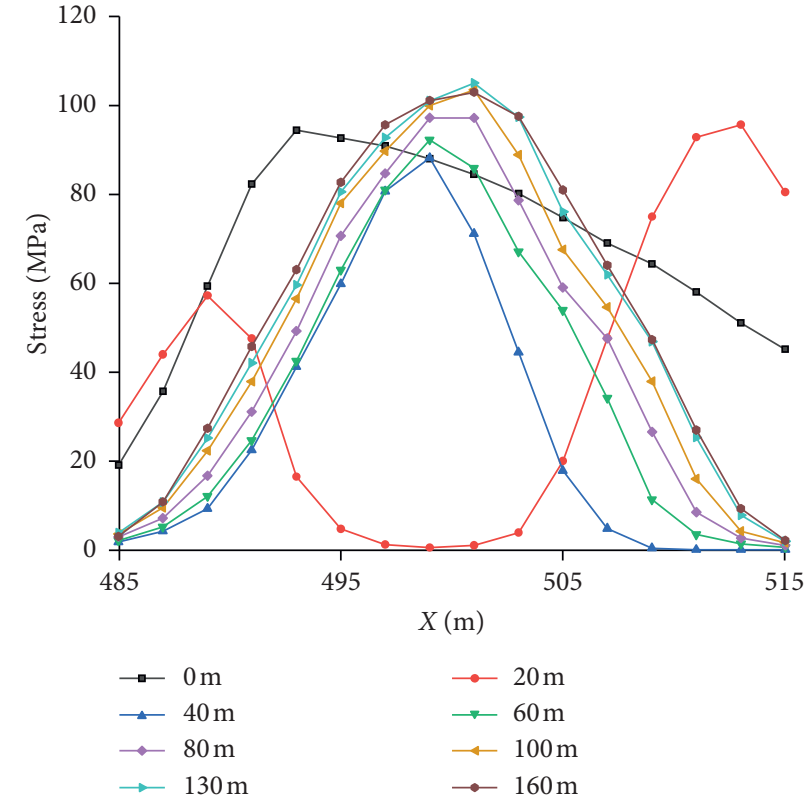

(a)

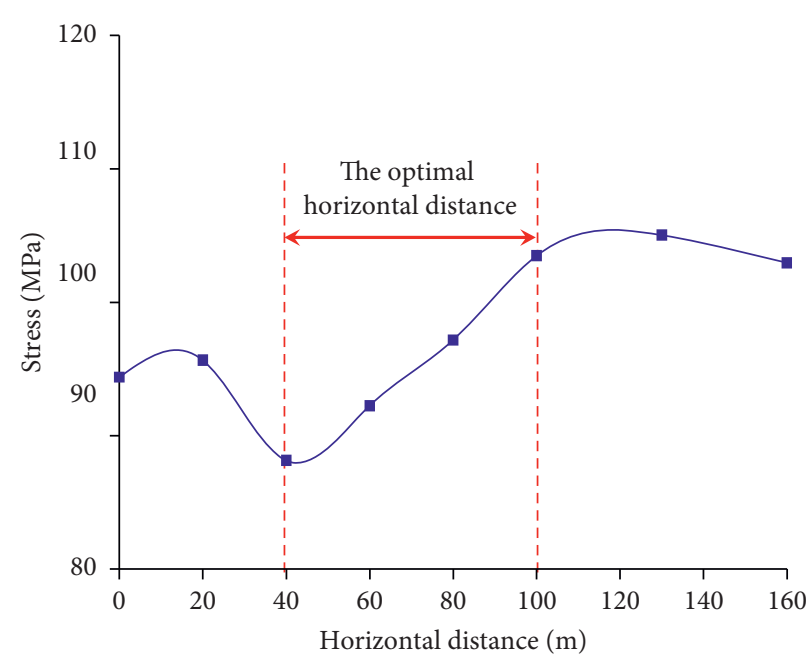

- Stress distribution under coal pillar

FIGURE 9: The distribution of vertical stress in the zone of influence of the remaining coal pillar during mining under different horizontal distances $L$. (a) Vertical stresses in the area of influence of the remaining coal pillar under different values of $L$. (b) The vertical peak stress in the zone of influence of the remaining coal pillar.

peak shift were established. The target layer A aims to determine the optimal horizontal distance $L$ of the working face in the protected seam; the main influencing factors that need to be considered are conditional layers $\mathrm{B}$ and factor layers $\mathrm{C}$. The former corresponds to the stress on coal before roadway excavation and the abutment pressures on the two roadways during mining and the stresses on the position below the remaining coal pillar; the latter refers to the vertical stresses on the roadways under different mining conditions. The AHP model is shown in Figure 10.

According to the relative importance of various conditional layers, a judgment matrix of conditional layers $B$ relative to the target layer $\mathrm{A}$ is determined (Table 2). The eigenvector $W_{i}$ and the maximum eigenvalue $\lambda_{\max }$ of the judgment matrix are 


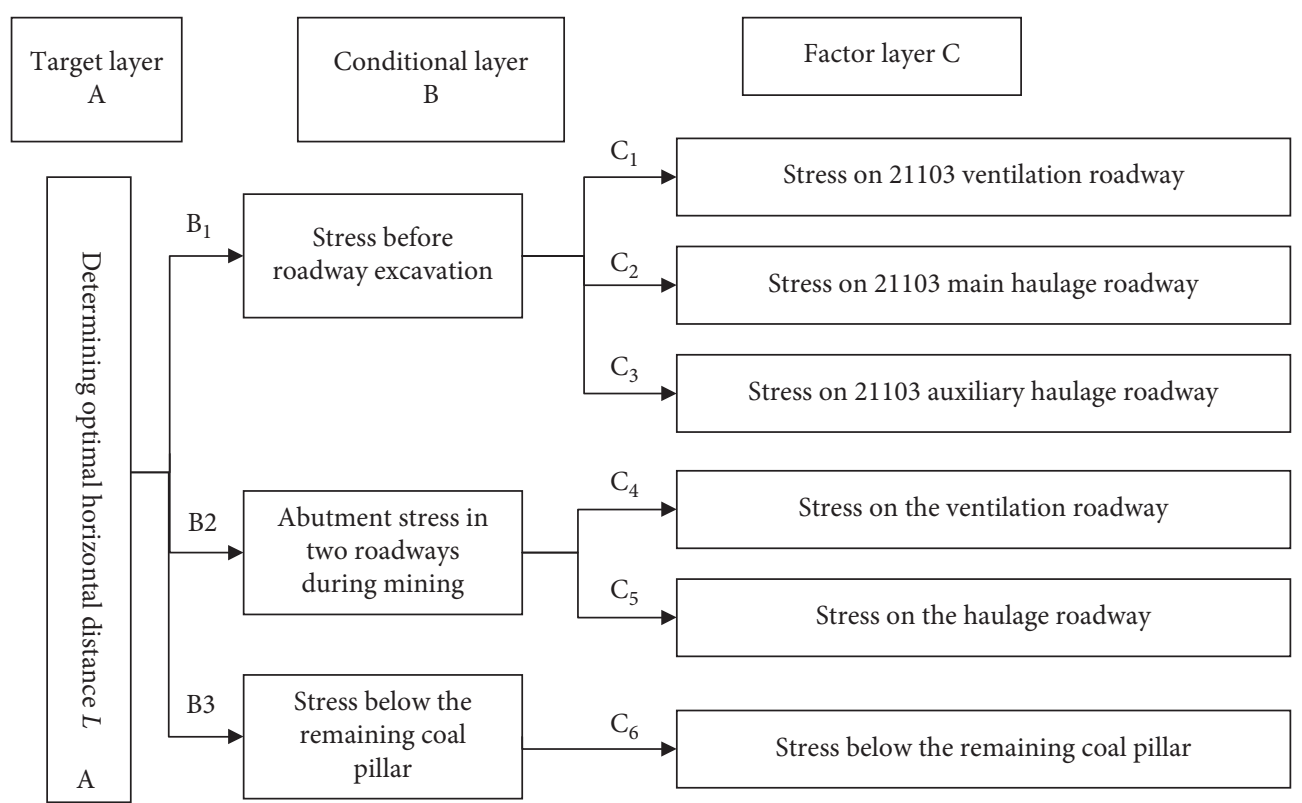

FIGURE 10: AHP model for distributing the working face in the protected seam for pressure relief by peak shift.

TABLE 2: The judgment matrix of the conditional layers $B$ relative to the target layer A.

\begin{tabular}{cccc}
\hline $\mathrm{A}$ & $\mathrm{B}_{1}$ & $\mathrm{~B}_{2}$ & $\mathrm{~B}_{3}$ \\
\hline $\mathrm{B}_{1}$ & 1 & $1 / 2$ & 3 \\
$\mathrm{~B}_{2}$ & 2 & 1 & 3 \\
$\mathrm{~B}_{3}$ & $1 / 3$ & $1 / 3$ & 1 \\
\hline
\end{tabular}

calculated by using the square root method according to formulae (9) and (10). where $a_{i j}, M_{i}, \bar{W}_{i}$, and $n$ represent the scale value of the $i$ th row in the $j$ th column of the judgment matrix, the product of values of $a_{i j}$ in each row, the $n$th root of $M_{i}$, and the dimension of the matrix, respectively. $W_{i}$ denotes the eigenvector of the judgment matrix, also the acquired weight of the conditional layer $\mathrm{B}$, and $\lambda_{\max }$ denotes the maximum characteristic root of the matrix.

$$
\begin{aligned}
M_{i} & =\prod_{j=1}^{n} a_{i j}, \\
\overline{W_{i}} & =\sqrt[n]{M_{i}}, \\
W_{i} & =\frac{\bar{W}_{i}}{\sum_{i=1}^{n} \overline{W_{i}}}, \\
\lambda_{\max } & =\sum_{i=1}^{n} \frac{(A W)_{i}}{n W_{i}},
\end{aligned}
$$

The calculated value of $\lambda_{\max }$ is subjected to a consistency check: when the consistency ratio of $\lambda_{\max }$ satisfies $\mathrm{CR}<0.1$, the matrix shows favourable consistency; otherwise, it is necessary to readjust the value of the judgment matrix. The value of $C R$ can be calculated according to the following formulae:

$$
\begin{aligned}
\mathrm{CI} & =\frac{\lambda_{\max }-n}{n-1}, \\
\mathrm{CR} & =\frac{\mathrm{CI}}{\mathrm{RI}},
\end{aligned}
$$

where $\lambda_{\max }, n$, and CI denote the maximum characteristic root of the matrix, the dimension of the matrix, and the consistency index for the matrix, respectively; RI refers to the mean of the random consistency indices, which is determined as $\mathrm{RI}=0.58$ for a three-dimensional matrix [21].

On this basis, the weight matrix $W_{\mathrm{B}}$ of the conditional layers $B$ relative to the target layer $A$ and its maximum eigenvalue $\lambda_{\max }$ are attained. The maximum eigenvalue satisfies the consistency check.

$$
\begin{aligned}
W_{B} & =\left\{\begin{array}{lll}
0.333 & 0.527 & 0.140
\end{array}\right\}, \\
\lambda_{\max } & =3.054, \\
\mathrm{CR} & =0.046<0.1 .
\end{aligned}
$$

Owing to the weight matrices of the factor layers $\mathrm{C}$ relative to the conditional layers $\mathrm{B}$ all being equal to 1 , the weight matrix $W_{C}$ of the factor layers $C$ relative to the target layer $\mathrm{A}$ is attained, which naturally satisfies the consistency check.

$$
W_{C}=\left\{\begin{array}{llllll}
0.111 & 0.111 & 0.111 & 0.264 & 0.264 & 0.139
\end{array}\right\} .
$$

As mentioned above, 50 to $75 \mathrm{~m}$ and 80 to $100 \mathrm{~m}$ satisfy two criteria, which are relatively optimal values. Thus, six groups of peak stresses under the horizontal distance $L$ within 40 to $100 \mathrm{~m}$ are weighted to determine the optimal value of $L$. The calculated results are shown in Table 3.

It can be found from Table 3 that the six groups of peak stresses in the 22103 working face show the lowest weighted value at $L=60 \mathrm{~m}$. This indicates that the overall stress is low during the excavation and mining of the working face in the 
TABLE 3: Calculation of the optimal value of the horizontal distance $L$.

\begin{tabular}{|c|c|c|c|c|c|c|c|}
\hline $\begin{array}{l}\text { Horizontal } \\
\text { distance } L\end{array}$ & $\begin{array}{c}\sigma_{1} \text { (excavation of } \\
\text { the ventilation } \\
\text { roadway) }\end{array}$ & $\begin{array}{c}\sigma_{2} \text { (excavation of } \\
\text { the main haulage } \\
\text { roadway) }\end{array}$ & $\begin{array}{c}\sigma_{3} \text { (excavation of } \\
\text { the auxiliary } \\
\text { haulage roadway) }\end{array}$ & $\begin{array}{c}\sigma_{4} \text { (mining of } \\
\text { the ventilation } \\
\text { roadway) }\end{array}$ & $\begin{array}{c}\sigma_{5} \text { (mining of } \\
\text { the main } \\
\text { haulage } \\
\text { roadway) }\end{array}$ & $\begin{array}{c}\sigma_{6} \text { (below the } \\
\text { remaining coal } \\
\text { pillar) }\end{array}$ & $\begin{array}{c}\text { Weighted } \\
\text { values of peak } \\
\text { stresses }\end{array}$ \\
\hline 40 & 2.9625 & 25.313 & 4.1839 & 55.187 & 69.855 & 88.137 & 48.865 \\
\hline 60 & 3.2465 & 5.1831 & 4.6743 & 57.012 & 73.528 & 92.237 & 48.738 \\
\hline 80 & 5.5786 & 3.6821 & 8.4367 & 59.993 & 68.492 & 97.166 & 49.391 \\
\hline 100 & 7.9059 & 6.4347 & 10.797 & 63.987 & 66.889 & 103.49 & 51.727 \\
\hline Weight & 0.111 & 0.111 & 0.111 & 0.264 & 0.264 & 0.139 & 1 \\
\hline
\end{tabular}

protected seam at horizontal distance $L$ of $60 \mathrm{~m}$, which is most beneficial to the prevention and control of rock burst in the roadways and working face.

\section{Conclusion}

(1) Against the background of the 2-1\# coal seam and the 2-2\# middle coal seam in Hulusu Coal Mine, a formula for the calculation of the stress on the coal after mining the protective seam was derived. The results show that, after mining the protective seam, three zones (area of influence of the advanced abutment pressure of coal, the remaining coal pillar, and stress-recovery in the goaf) subject to increasing stress, and two symmetric zones subject to decreasing stress were formed. By utilising limit equilibrium theory, the stresses in the zones of influence of the advanced abutment pressure and that of the remaining coal pillar were measured and estimated according to the range of the plastic zone. The stress in the goaf could be simplified into symmetrical, triangular loads, in which the stress in the middle part of the goaf recovered to 0.82 times the in situ stress.

(2) Based on the assumption of a semi-infinite plane, the formula for the distribution of the vertical stress applied to the protected seam after mining the protective seam was derived: numerical simulation was then applied to its solution. The results show that the easiest and safest roadway excavation could be undertaken when the horizontal distance $L$ between the working face in the protected seam and that in the upper coal seam is in the range of 50 to $75 \mathrm{~m}$; at $L=80$ to $140 \mathrm{~m}$, the mining-induced disturbance exerted the least influence on the two roadways; the influence of the remaining coal pillar on the mining of the working face was minimised at $L=40$ to $100 \mathrm{~m}$.

(3) Based on the concept of the AHP method, the optimal value of the horizontal distance $L$ when three criteria are mutually contradictory was analysed. On this basis, weights for the three criteria were attained and the weighted values of the peak stress under different values of $L$ were calculated. The results reveal that the overall stress was lowest during excavation and mining of the working face in the protected seam when $L=60 \mathrm{~m}$, which was the most conducive to the prevention and control of rockburst accidents in the roadways and working face.

\section{Data Availability}

All the data, models, and code generated or used during the study appear in the submitted article.

\section{Conflicts of Interest}

The authors declare that there are no conflicts of interest regarding the publication of this paper.

\section{Acknowledgments}

This work was supported and financed by China Postdoctoral Science Foundation (Grant no. 2018M643692), the National Natural Science Foundation of China (Grant no. 51904235), and the National Science Basic Research Plan in Shaanxi Province of China (Grant no. 2019JQ-487).

\section{References}

[1] G.-A. Zhu, L.-M. Dou, C.-B. Wang, Z.-W. Ding, Z.-J. Feng, and F. Xue, "Experimental study of rock burst in coal samples under overstress and true-triaxial unloading through passive velocity tomography," Safety Science, vol. 117, pp. 388-403, 2019.

[2] Z.-L. Li, X.-Q. He, L.-M. Dou, D.-Z. Song, G.-F. Wang, and $\mathrm{X} .-\mathrm{L} . \mathrm{Xu}$, "Investigating the mechanism and prevention of coal mine dynamic disasters by using dynamic cyclic loading tests," Safety Science, vol. 115, pp. 215-228, 2019.

[3] Y. Xue, Z. Z. Cao, and Z. H. Li, "Destabilization mechanism and energy evolution of coal pillar in rockburst disaster," Arabian Journal of Geoscience, vol. 13, p. 557, 2020.

[4] F. Wang and R. Kaunda, "Assessment of rockburst hazard by quantifying the consequence with plastic strain work and released energy in numerical models," International Journal of Mining Science and Technology, vol. 29, no. 1, pp. 93-97, 2019.

[5] M. Christopher and G. Michael, "Pillar design and coal burst experience in Utah Book Cliffs longwall operations," International Journal of Mining Science and Technology, vol. 31, no. 1, pp. 33-41, 2021.

[6] Y. L. Chen, J. P. Zuo, and D. J. Liu, "Experimental and numerical study of coal-rock bimaterial composite bodies under triaxial compression," International Journal of Coal Science \& Technology, vol. 5, pp. 1-12, 2021.

[7] Z. H. Jiao, G. M. Tao, and H. Wang, "Overburden strata movement and fissure evolution in lower protective layer in 
Jincheng mining district," Journal of Mining and Safety Engineering, vol. 34, no. 1, pp. 85-90, 2017.

[8] W. Wang, Y. P. Chen, and L. Yuan, "Floor fracture evolution and relief gas drainage timeliness in deeper underground short-distance upper protective coal seam extraction," Journal of China Coal Society, vol. 41, no. 1, pp. 138-148, 2016.

[9] Z. S. Du, B. T. Qin, and Y. C Fan, "A reliability evaluation model of exploitation efficiency of the protective layer and its application," Journal of Mining and Safety Engineering, vol. 34, no. 1, pp. 185-191, 2017.

[10] Z.-L. Li, L.-M. Dou, W. Cai, G.-F. Wang, Y.-L. Ding, and Y. Kong, "Roadway stagger layout for effective control of gob-side rock bursts in the longwall mining of a thick coal seam," Rock Mechanics and Rock Engineering, vol. 49, no. 2, pp. 621-629, 2016.

[11] L. Cheng, Z. Ge, J. Chen, L. Zou, Y. Cheng, and S. Xiao, "Hydraulic fracturing and its effect on gas extraction and coal and gas outburst prevention in a protective layer: a case study in China," International Journal of Oil, Gas and Coal Technology, vol. 23, no. 4, p. 427, 2020.

[12] A. He, H. Fu, B. Huo, and C. Fan, "Permeability enhancement of coal seam by lower protective layer mining for gas outburst prevention," Shock and Vibration, vol. 2020, pp. 1-12, 2020.

[13] H. P. Xie, H. W. Zhou, and J. F. Liu, "Mining-induced mechanical behavior in coal seams under different mining layouts," Journal of China Coal Society, vol. 36, no. 7, pp. 1067-1074, 2011.

[14] X. Q. Wu, L. M. Dou, and C. G. Lv, "Study on upper liberated seam mining to pressure releasing function of low seam," Coal Science and Technology, vol. 40, no. 3, pp. 28-92, 2012.

[15] C. G. Lv, L. M. Dou, and C. H. Xu, "Numerical simulation of protective mechanism of upper protective seam mining," Coal Mining Technology, vol. 16, no. 2, pp. 12-15, 2011.

[16] L. F. Wang, F. X. Jiang, and Z. X. Yu, "Similar material simulation experiment on destressing effects of the deep thick coal seam with high burst liability after mining upper and lower protective seams," Chinese Journal of Geotechnical Engineering, vol. 31, no. 3, pp. 442-446, 2009.

[17] Z. Tang, Y. S. Pan, and Z. H Li, "Numerical simulation on destressing effects of the deep thick coal seam with high burst liability after mining liberated seams," Chinese Journal of Geological Hazard and Control, vol. 22, no. 1, pp. 128-132, 2011.

[18] L. L. Pang, X. F Xu, and L. Si, "Analysis of prevention mechanism of upper protective seam mining on rockburst induced by thick conglomerate," Rock and Soil Mechanics, vol. 37, no. S2, pp. 120-128, 2016.

[19] M. G. Qian and P. W. Shi, Mine Pressure and Ground Control, China University of Mining and Technology Press, Xuzhou, China, 2010.

[20] W. X. Wang, Cover Stress Re-establishment and its Permeability Evolution in Mining-Induced Fracture Rock Mass, China University of Mining and Technology, Xuzhou, China, 2014.

[21] H. J. King and B. N. Whittaker, "A review of current knowledge on roadway behavior, especially the problems on which further information is required," in Proceedings of the Symposium on Strata Control in Roadway, pp. 73-90, IME, London, UK, June 1970.

[22] C. Mark, "Analysis of longwall pillar stability (ALPS): an update,"vol. 9315, pp. 238-249, in Proceedings of the Workshop on Coal Pillar Mechanics and Design, vol. 9315, pp. 238-249, US Department of the Interior, Bureau of Mines, IC, Pittsburgh, PA, USA, June 1992.

[23] D. S. Choi and D. L. McCain, "Design of longwall systems," Transactions of the Society of Mining Engineers of AIME, vol. 268, pp. 1761-1764, 1980. 